\title{
The Source of Plasma Dihydrotestosterone in Man
}

\author{
T. ITO and R. HoRTON \\ From the Department of Medicine, University of Southern California, School \\ of Medicine, Los Angeles, California 90033
}

A в S T R A C T The source of plasma dihydrotestosterone (DHT) (17 $\beta$-hydroxy-5 $\alpha$-androstan-3-one) in humans has been investigated by infusing two potential peripheral precursors, testosterone $(\mathrm{T})$ and androstenedione (A). Metabolic clearance rates (MCR), conversion ratios (CR), transfer constants $(\rho)$, and blood production rates $\left(\mathrm{P}_{\mathbf{B}}\right)$ were calculated. Plasma testosterone and dihydrotestosterone were measured by competitive binding techniques. The $\mathrm{MCR}^{\mathrm{DHT}}$ was $652 \pm 35$ (SD) liters/day in five males and $314 \pm 63$ (SD) liters/day in four adult females. In each individual, the $\mathrm{MCR}^{\mathrm{DHT}}$ was significantly lower than $\mathrm{MCR}^{\mathrm{T}}$ as predicted by testosterone-binding protein affinity studies. The $\mathrm{P}_{\mathbf{B}}{ }^{\text {DHT }}$ was $302 \pm 65$ (SD) $\mu \mathrm{g} /$ day in males and $56 \pm 26 \mu \mathrm{g} /$ day in females. Testosterone and androstenedione are precursors (prehormones) for plasma dihydrotestosterone. The conversion ratio $\mathrm{CR}_{\mathbf{B B}}{ }^{\mathrm{T}-\mathrm{DET}}$, calculated as the ratio of counts per minute per liter of plasma of product to precursor after infusion of labeled precursor, was $5.6 \pm 0.6$ (SD) \% (six subjects) in the male and 3.5 \pm 0.4 (sD) \% (four subjects) in the female. $\mathrm{CR}_{\mathrm{BB}}{ }^{\mathrm{A}-\mathrm{DHT}}$ after androstenedione infusion to three female subjects averaged $9.2 \%$. No dihydrotestosterone back conversion was detected $(<0.2 \%)$. The transfer constants were $[\rho]_{\mathrm{BB}}{ }^{\mathrm{T}-\mathrm{DHT}}, 3.9 \pm 1.0 \%$ (male) and $1.7 \pm 0.6 \%$ (female), and $[\rho]_{\mathbf{B B}^{\mathrm{A}}}{ }^{\mathrm{DHT}}$ average was $13.3 \%$ in three female subjects. Using either plasma testosterone and dihydrotestosterone values from our subjects and mean androstenedione values as reported in the literature, approximate contributions can be calculated. Testosterone conversion accounts for at least $70 \%$ of plasma DHT in the male, but less than $20 \%$ in the normal female. Androstenedione appears to be a major prehormone of plasma dihydrotestosterone accounting for at least twothirds plasma dihydrotestosterone by peripheral conversion in adult females. In three normal women undergoing tubal ligation, there was an unimpressive gradient

This work was presented in part at the 52nd Meeting of the Endocrine Society, June 1970 in St. Louis, Mo. Program page 73.

Received for publication 29 December 1970 and in revised form 31 March 1971. between ovarian vein and peripheral plasma dihydrotestosterone. It is suggested that dihydrotestosterone in the blood does not arise from direct secretion but may reflect events occurring in peripheral androgen target tissues.

\section{INTRODUCTION}

It is now clearly established that certain sex steroids are interconvertible in the body. The rates of interconversion vary from tissue to tissue. Of great importance is the observation that conversion rates as measured in blood differ from those calculated by the analysis of urinary metabolites (1). The study of interconverting steroid pairs has indicated that a biologically secreted active steroid hormone in blood may be derived from an inactive secreted precursor (prehormone). Examples are the interconverting pairs of androstenedione-testosterone (2), ${ }^{1}$ estrone-estradiol (3), and androgen-estrogen (4).

In a series of in vitro studies, Wilson, Bruchovsky, and Chatfield found that testosterone was efficiently converted by androgen target tissues to the reduction product, dihydrotestosterone. ${ }^{1}$ This steroid is bound with much higher affinity to nuclear chromatin than is testosterone and may be the effective tissue androgen (5).

We have recently published an accurate competitive binding method for the measurement of dihydrotestosterone in peripheral plasma (6). This biologically active androgen may be a secreted hormone or may reflect peripheral conversion of other secreted androgens. Our study concludes that blood dihydrotestosterone arises from the peripheral conversion of two different secretory products.

\footnotetext{
${ }^{1}$ Systematic nomenclature for trivial names used in this paper: dihydrotestosterone, $17 \beta$-hydroxy- $5 \alpha$-androstan-3-one ; $5 \beta$-DHT, $17 \beta$-hydroxy- $5 \beta$-androstan-3-one ; testosterone, $17 \beta$ hydroxy-4-androsten-3-one; androstenedione, 4-androstene3,17-dione ; estradiol, 1,3,5(10)-estratriene-3,17 $\beta$-diol ; estrone, 1,3,5(10)-estratriene-3-o1-17 $\beta$-one.
} 


\section{METHODS}

Infusion procedure. Normal adult men and women were infused with testosterone- $1,2{ }^{3} \mathrm{H}$ (T), ${ }^{2}$ androstenedione (A), or dihydrotestosterone (DHT) by the constant infusion technique as previously described (2). 2-hr infusions were given after the patients were kept supine for a $1 \mathrm{hr}$ control period. All experiments were started between 8 and 9 a.m. A priming dose of $1-3 \mu \mathrm{Ci}$ was given intravenously, and a constant infusion of $10-30 \mu \mathrm{Ci}$ of the ${ }^{3} \mathrm{H}$-labeled steroid in $50 \mathrm{ml}$ of a $6 \%$ ethanol solution in normal saline was administered through Teflon tubing as previously described (2). Control blood samples were drawn for measurement of plasma testosterone and dihydrotestosterone, and infusion samples were obtained at 105 and $120 \mathrm{~min}$. The plasma was then frozen immediately at $-20^{\circ} \mathrm{C}$.

Analy'sis of precursor and product radioactivity. $20-30 \mathrm{ml}$ of plasma was added to a flask containing testosterone-4- ${ }^{14} \mathrm{C}$ $(300 \mathrm{cpm})$ and dihydrotestosterone $(100 \mathrm{cpm})$ for the $\mathrm{T}-1$, $2-{ }^{3} \mathrm{H}$ studies and androstenedione $-4-{ }^{14} \mathrm{C}$ for the androstenedione- $1,2-{ }^{3} \mathrm{H}$ infusions. The plasma was then alkalinized with $2 \mathrm{ml}$ of $4 \mathrm{~N} \mathrm{NaOH}$, and the steroids were extracted two times, each time with three volumes of methylene chloride. The extract was then washed twice with $10 \mathrm{ml}$ of $1 \mathrm{~N}$ $\mathrm{NaOH}$ and twice again with $10 \mathrm{ml}$ water, transferred to a round bottom flask, and evaporated in a Rinco type vacuum setup. $6 \mathrm{ml}$ of $70 \%$ methanol and $12 \mathrm{ml}$ of petroleum ether (bp 75.8-96.4 $\mathrm{C}$ ) were added, shaken, and the petroleum ether was removed and discarded. The remaining methanol was evaporated to dryness.

Paper chromatographic purification was carried out using the Bush B-3 and the Bush A paper systems as previously described (6). In a typical $2 \mathrm{hr}$ run in the B-3 system, testosterone moved $15 \mathrm{~cm}$ and DHT ran $23 \mathrm{~cm}$. The samples corresponding to $\pm 1.5 \mathrm{~cm}$ from the center of the parallel standards (which were located by scanning) were then cut out and eluted with $5 \mathrm{ml}$ methanol using the syringe technique.

After the first chromatogram, the separated steroid samples were acetylated overnight by adding $0.2 \mathrm{ml}$ pyridine and $0.2 \mathrm{ml}$ acetic anhydride. After drying the acetylated samples, they were separately spotted on Whatman paper No. 2 and run in the A system for $2 \mathrm{hr}$. The acetylated steroids were located against parallel ${ }^{3} \mathrm{H}$-acetylated standards passed through a strip scanner. Although androstenedione moves the same as dihydrotestosterone in the Bush 3 system, these two testosterone conversion products are completely separated by the acetylation procedure (androstenedione runs $10 \mathrm{~cm}$, dihydrotestosterone acetate runs $20 \mathrm{~cm}$ ).

The following infusion studies were performed: $(a)$ testosterone $-{ }^{3} \mathrm{H}$, six males and four females; $(b)$ dihydrotestosterone $-{ }^{3} \mathrm{H}$, five males and four females; and $(c)$ androstenedione- ${ }^{3} \mathrm{H}$, three females.

Radioactive counting. All counting was performed with a Nuclear-Chicago scintillation spectrometer. The characteristics for counting tritium and carbon-14 are as described previously (4). An analysis of counting errors for this type of study has been extensively described elsewhere (7).

Radioactive steroids. Testosterone- $1,2-{ }^{3} \mathrm{H}$, androstenedione (SA $44 \mathrm{Ci} / \mathrm{mmoles}$ per liter), and steroids $-{ }^{14} \mathrm{C}$ were obtained from New England Nuclear Corp., Boston, Mass.

\footnotetext{
${ }^{2}$ Abbreviations used in this paper: A, androstenedione; $\mathrm{BB}$, blood to blood; $\mathrm{CR}$, conversion ratio; $\mathrm{DHT}$, dihydrotestosterone; $\mathrm{MCR}$, metabolic clearance rate; $\mathrm{P}_{\mathbf{B}}$, blood production rate; $\mathrm{PR}$, production rate; $\rho$, transfer constant; $\mathrm{T}$, testosterone.
}

All steroids used were purified by paper chromatography in the Bush B-3 system. Evidence for radiochemical purity has been previously presented $(4,6)$.

Dihydrotestosterone- $4-{ }^{14} \mathrm{C}$ was made from previously purified testosterone-4- ${ }^{14} \mathrm{C}$. Approximately $100 \mu \mathrm{Ci}$ testosterone${ }^{14} \mathrm{C}$ was taken to dryness under vacuum, and then $0.1 \mathrm{ml}$ ethanol and $1 \mathrm{ml} \mathrm{NH} \mathrm{NH}_{4} \mathrm{OH}$ were added to the flask. Potassium metal (J. T. Baker Chemical Co., Phillipsburg, N. J.) previously cut into small strips (1-2 mm) under petroleum ether, was slowly added to the flask. Addition was continued for several hours to generate $\mathrm{H}_{2} .1 \mathrm{ml}$ water was then added to stop this reaction, and the ammonium hydroxide was evaporated under vacuum. The solution was neutralized with dropwise acetic acid and steroids extracted with two volumes of methylenedichloride, and the dihydrotestosterone $-{ }^{14} \mathrm{C}$ was purified by repeated paper chromatography. The other possible reduction product, $5 \beta$-DHT, was separated from DHT in both the B-3 and Bush A paper systems because of its greater polarity.

Proof of radiochemical purity of the dihydrotestosterone${ }^{3} \mathrm{H}$ and dihydrotestosterone $-{ }^{14} \mathrm{C}$ was obtained by mixing the purified DHT-1,2- ${ }^{3} \mathrm{H}$ with the prepared and purified DHT${ }^{4}-{ }^{14} \mathrm{C} \quad\left({ }^{3} \mathrm{H} /{ }^{14} \mathrm{C}\right.$ ratio 3.18$)$. The remaining mixture was chromatographed in the $\mathrm{B}-3$ system $\left({ }^{3} \mathrm{H} /{ }^{14} \mathrm{C}\right.$ ratio 3.16$)$. Evidence for attainment of equilibrium after infusion for 100 $\mathrm{min}$ for both testosterone and androstenedione has been previously reported (2).

Estimation of plasma testostcrone and dihydrotestosterone. Plasma testosterone and dihydrotestosterone were measured in samples obtained at the beginning of the infusion by competitive binding methods developed in our laboratory $(6,8)$. Peripheral and ovarian vein plasma from three women undergoing tubal ligation were assayed for dihydrotestosterone.

Evidence for radiochemical purity of dihydrotestosterone${ }^{3} \mathrm{H}$ isolated from plasma during infusion. After a constant infusion of testosterone- ${ }^{3} \mathrm{H}$, a pool of plasma was made, and DHT $-4-{ }^{14} \mathrm{C}$ and $\mathrm{T}$ were added. The sample was then extracted, chromatographed on the Bush B-3 system, acetylated, and run as in the standard method in the Bush A system. The remaining acetylated sample was then chromatographed in the B-3 system. The calculated isotope ratios were 4.0 and 3.7 , respectively, which could be accounted for by the error of counting at that level.

Proof of the radiochemical purity of $\mathrm{DHT}-{ }^{3} \mathrm{H}$ after infusion of androstenedione $-{ }^{3} \mathrm{H}$ was obtained by the same technique. A pool of plasma after an infusion of androstenedione${ }^{3} \mathrm{H}$ was prepared. The plasma with dihydrotestosterone $-{ }^{14} \mathrm{C}$ was purified as in the regular procedure which included Bush B-3 paper chromatography, acetylation of the sample running parallel to standard dihydrotestosterone, and rechromatography in the Bush A system. One-third was taken for counting $\left({ }^{3} \mathrm{H} /{ }^{14} \mathrm{C}=3.05\right)$. The remaining sample was then further purified in the Bush A system. No significant change was observed in the isotope ratio $\left({ }^{3} \mathrm{H} /{ }^{14} \mathrm{C}=3.02\right)$.

Evidence that equilibrium in plasma was attained during the constant infusion. Analysis of radioactivity as the purified steroid- ${ }^{3} \mathrm{H}$ corrected for recovery after the priming dose was determined as previously described for testosterone and androstenedione $(2,4)$. In the six infusions where the value at $105 \mathrm{~min}$ is compared with the respective 120 -min samples, the mean value at $120 \mathrm{~min}$ was $96.6 \pm 2.7$ ( $\mathrm{SE}$ ) student's test $(t=1.16)$. Also, if an individual ratio $(120 / 105 \mathrm{~min}$ value $)$ for each infusion is calculated and if the mean ratio is 0.96 , the $95 \%$ confidence interval is equal to $0.83-1.09$. This indicates that this ratio is not significantly different from 1.0 . 
Calculation of metabolic clearance, production rates, and interconversion rates. Metabolic clearance rates (MCR), conversion ratios $(\mathrm{CR})$, and transfer constants, were calculated as previously described (2). The blood production rate $(P R)$ is the product of the mean metabolic clearance rate and plasma concentration. In this study as in previous investigations, the production rate $(P R)$ was calculated using the steroid concentration in plasma and metabolic clearance obtained during the $2 \mathrm{hr}$ morning infusion.

In previous studies only the labeled precursor was infused, and calculations of the transfer constants ( $[\rho]^{\text {Pre-Prod}}$ ) used the mean metabolic clearance value of the product from similar individuals (2-4) since :

$$
[\rho]^{\text {Pre-Prod }}=\frac{\mathrm{MCR}^{\text {Prod }} \cdot \overline{\mathrm{x}}^{\text {Prod }}}{\mathrm{R}^{\text {Pre }}}=\frac{\mathrm{MCR}^{\text {Prod }} \cdot \overline{\mathbf{x}}^{\text {Prod }}}{\mathrm{MCR}^{\text {Pre }} \cdot \overline{\mathbf{x}}^{\text {Pre }}}
$$

where $\overline{\mathbf{x}}$ is the mean level of radioactivity as precursor (Pre) or product (Prod) and $R$ is the rate of infusion of precursor (2). In the present investigation, both labeled precursor and product were separately infused into the same patient under this same condition which should yield more accurate data for the group studied.

The fraction of the blood production rate of dihydrotestosterone $\left(\mathrm{P}_{\mathbf{B}}{ }^{\mathrm{DHT}}\right)$ coming from the blood production rate of testosterone $\left(P_{B}{ }^{T}\right)$ is given by the expression:

$$
\frac{\mathrm{P}_{\mathrm{B}} \mathrm{T} \cdot[\rho]_{\mathrm{BB}}{ }^{\mathrm{T}-\mathrm{DHT}}}{\mathrm{P}_{\mathrm{B}} \mathrm{DHT}} \div 1-[\rho]_{\mathrm{BB}}{ }^{\mathrm{T}-\mathrm{DHT}}[\rho]_{\mathrm{BB}} \mathrm{DHT}-\mathrm{T}
$$

where $\mathrm{P}_{\mathbf{B}}{ }^{T} \cdot[\rho]_{\mathbf{B B}}{ }^{\mathrm{T}-\mathrm{DHT}}$ is the production of dihydrotestosterone in the blood arising from the production of testosterone (9). Usually in this type of calculation, a correction $\left(1 / 1-[\rho]_{\mathbf{B B}}{ }^{\text {T-DHT }}[\rho]_{\mathbf{B B}}{ }^{\text {DHT-T }}\right)$ has to be made because some of the precursor has arisen initially from the product. However, with the result presented here, $[\rho]_{\mathbf{B B}}{ }_{\text {DHT-T }}$ is undetectable and the correction is unnecessary, and so the fraction of total $\mathrm{P}_{\mathbf{B}}{ }^{\mathrm{DHT}}$ made in this manner is expressed by the formula

$$
\frac{\mathrm{P}_{\mathrm{B}}^{\mathrm{T}} \cdot[\rho]_{\mathrm{BB}}^{\mathrm{T}-\mathrm{DHT}}}{\mathrm{P}_{\mathrm{B}}^{\mathrm{DHT}}} .
$$

\section{RESULTS}

Metabolic clearance rates. Metabolic clearance rates of dihydrotestosterone $\left(\mathrm{MCR}^{\mathrm{DHT}}\right)$ by continuous infusion were $652 \pm 35$ (SD) liters/day in five male subjects and $314 \pm 63$ (SD) liters/day in four female adults (Table I). The different values in males and females are significantly different $(P<0.02)$ and remain so even if corrected for sex differences in surface area.

Metabolic clearance of testosterone $\left(\mathrm{MCR}^{\mathbf{T}}\right)$ was 976 \pm 57 (SD) liters/day in six males and $667 \pm 70$ (SD) liters/day in four females. These $\mathrm{MCR}^{\mathbf{T}}$ values were similar to those previously reported by our group (2, 4). There is a significant difference between $M_{C} R^{\text {DHT }}$ and $\mathrm{MCR}^{\mathbf{T}}$ values in males and females $(P<0.05)$.

Plasma concentration of dihydrotestosterone and testosterone. Plasma dihydrotestosterone levels were 46 \pm 19 (SD) $\mathrm{m} \mu \mathrm{g} / 100 \mathrm{ml}$ in five males and $17 \pm 7$ (SD) $\mathrm{m} \mu \mathrm{g} / 100 \mathrm{ml}$ in four females. Plasma testosterone was $544 \pm 208$ (SD) $\mathrm{m} \mu \mathrm{g} / 100 \mathrm{ml}$ in six male and $40 \pm 9$ (sD) $\mathrm{m} \mu \mathrm{g} / 100 \mathrm{ml}$ in the four female subjects. These plasma values for both androgens are indistinguishable from normal values reported by us from a much larger group of normal individuals (6).

Blood production rates. Production rates were calculated individually as the product of MCR and plasma concentration. The blood production rate of dihydrotestosterone was $302 \pm 65 \mu \mathrm{g} /$ day in adult males and $56 \pm 26 \mu \mathrm{g} /$ day in females. Testosterone production rates were $5130 \pm 740 \mu \mathrm{g} /$ day in males and $267 \pm 37$ $\mu \mathrm{g} /$ day in females.

Conversion ratios and transfer constants in blood. The conversion ratio, $\mathrm{CR}_{\mathbf{B B}}{ }^{\mathbf{T}-\mathbf{D H T}}$, was calculated as the ratio of counts per minute per liter of plasma of product

\begin{tabular}{|c|c|c|c|c|c|c|c|c|}
\hline \multirow[b]{2}{*}{ Subject } & \multirow[b]{2}{*}{ Sex } & \multirow{2}{*}{$\begin{array}{c}\text { Infused } \\
\text { DHT- }{ }^{3} \mathrm{H}\end{array}$} & \multicolumn{3}{|c|}{ DHT-8 H } & \multirow[b]{2}{*}{ MCRDHT } & \multirow[b]{2}{*}{$\begin{array}{l}\text { Plasma } \\
\text { DHT }\end{array}$} & \multirow[b]{2}{*}{ PRDHT } \\
\hline & & & $105 \mathrm{~min}$ & $120 \mathrm{~min}$ & Mean & & & \\
\hline & & $c p m / d a y$ & \multicolumn{3}{|c|}{$c p m /$ liter } & liters/day & $m \mu g /$ liter & $\begin{array}{c}\mu g \text { blood/ } \\
\text { day }\end{array}$ \\
\hline S. & M & $19 \times 10^{6}$ & 27,000 & 29,000 & 28,000 & 691 & 556 & 384 \\
\hline $\mathrm{R}$. & M & $24 \times 10^{6}$ & 34,000 & 37,000 & 35,900 & 689 & 409 & 282 \\
\hline Sc. & M & $23 \times 10^{6}$ & 35,000 & 38,000 & 36,500 & 629 & 756 & 475 \\
\hline A. & M & $19 \times 10^{6}$ & 25,000 & 27,000 & 26,000 & 728 & 389 & 283 \\
\hline I. & $\mathbf{M}$ & $40 \times 10^{6}$ & 77,000 & 75,000 & 76,000 & 526 & 163 & 86 \\
\hline \multicolumn{3}{|c|}{ Mean \pm SD } & & & & $652 \pm 35$ & $455 \pm 196$ & $302 \pm 65$ \\
\hline L. & $\mathrm{F}$ & $43 \times 10^{6}$ & 188,000 & 173,000 & 80,000 & 243 & 188 & 46 \\
\hline V. & $\mathrm{F}$ & $80 \times 10^{6}$ & \multicolumn{2}{|c|}{ Pool } & 219,000 & 372 & 89 & 33 \\
\hline W. & $\mathrm{F}$ & $57 \times 10^{6}$ & \multicolumn{2}{|c|}{ Pool } & 120,000 & 437 & 277 & 121 \\
\hline Sp. & $\mathrm{F}$ & $18 \times 10^{6}$ & \multicolumn{2}{|c|}{ Pool } & 90,000 & 204 & 126 & 24 \\
\hline \multicolumn{3}{|c|}{ Mean $\pm S D$} & & & & $314 \pm 63$ & $170 \pm 71$ & $56 \pm 26$ \\
\hline
\end{tabular}

TABLE I

Data for the Determination of $M C R^{\mathrm{DHT}}$ and $P R^{\mathrm{DHT}}$ in Men and Women 


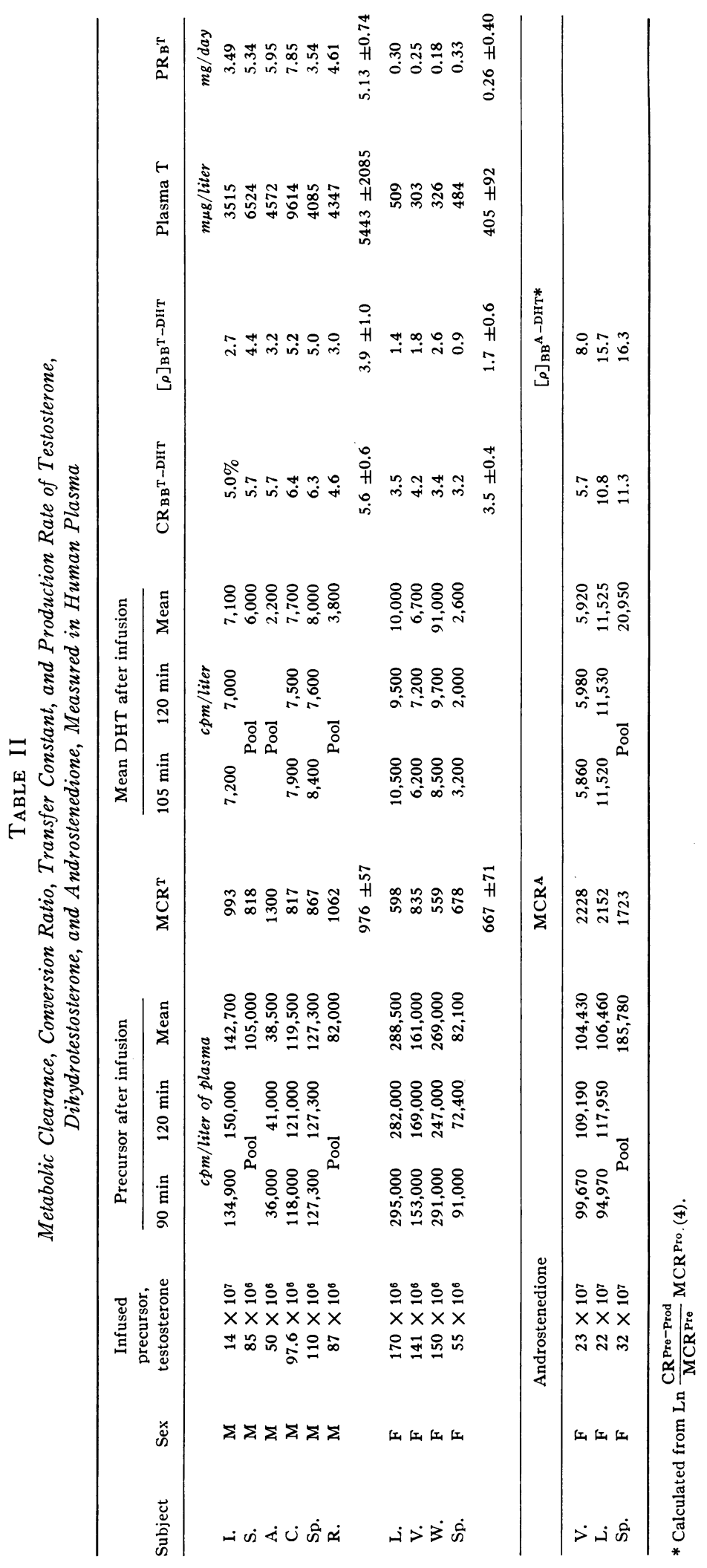


to precursor both corrected for recovery after infusion of the labeled precursor. The conversion ratio of dihydrotestosterone/testosterone ( $\mathrm{CR}_{\mathbf{B B}}{ }^{\mathrm{T}-\mathrm{DHT}}$ ) after infusion of labeled testosterone was $5.6 \pm 0.6$ ( $\mathrm{SD}$ ) \% (six subjects) in males and $3.5 \pm 0.4$ (SD) \% (four subjects) in females. $\mathrm{CR}_{\mathbf{B B}}{ }^{\mathbf{A}-\mathbf{D H T}}$ after infusion of androstenedione to three females averaged 9.2\%. After infusion of labeled dihydrotestosterone, no tritium was detectable as testosterone indicating that the conversion $\mathrm{CR}_{\mathbf{B B}}{ }^{\mathrm{DHT}-\mathrm{T}}$ is negligible $(<0.2 \%)$. The transfer constants for testosterone $[\rho]_{\mathbf{B B}}{ }^{\mathrm{T}-\mathrm{DHT}}$ and androstenedione $[\rho]_{\mathbf{B B}}{ }^{\mathrm{A}-\mathrm{DHT}}$ are illustrated in Table II. [ $\rho]_{\mathbf{B B}}{ }^{\text {T-DHT }}$ is $3.9 \pm 1.0 \%$ in the male and $1.7 \pm 0.6 \%$ in the female. $[\rho]_{\mathbf{B B}}{ }^{\mathrm{A}-\mathrm{DHT}}$ averages 13.3 in the female.

The contribution of testosterone and androstenedione to blood dihydrotestosterone. Taken together the data allow calculation of the contribution of each blood precursor to product since:

$$
\% \text { DHT from } \mathrm{T}=\frac{\text { Plasma } \mathrm{T} \cdot \mathrm{CR}^{\mathrm{T}-\mathrm{DHT}}}{\text { Plasma DHT }} .
$$

The contribution of testosterone to plasma concentration would then be $31 \mathrm{~m} \mu \mathrm{g} / 100 \mathrm{ml}$ in the male but only $1.4 \mathrm{~m} \mu \mathrm{g} / 100$ in the female. No detectable $(<0.2 \%)$ back conversion was found. These data suggest that approximately $70 \%$ of blood DHT in the male but only $8 \%$ in the female is derived from the peripheral conversion of testosterone.

If the conversion ratio for androstenedione $\left(\mathrm{CR}_{\mathbf{B B}}{ }^{\mathrm{A}-\mathrm{DHT}}\right)$ is considered with normal plasma androstenedione values in the female of $159 \mathrm{~m} \mu \mathrm{g} / 100 \mathrm{ml}$ previously reported (10), then the data suggest that approximately two-thirds of blood dihydrotestosterone in the female is derived from androstenedione. The direct measurement of DHT in peripheral and ovarian vein plasma indicates minimal ovarian secretion ( Table III).

\section{DISCUSSION}

Steroids, when compared with proteins, are relatively simple planar molecules. Yet studies with androgens, estrogens, or mineralocorticoids have demonstrated a high degree of stereospecificity with the tissue-binding (receptor) proteins (11-14). The sex steroids are also bound to plasma proteins. In general, there has been excellent correlation between binding affinity and biological activity. It was surprising when we and others $(11,12)$ observed that dihydrotestosterone had approximately twice the binding affinity to the sex hormonebinding plasma protein as did testosterone, although testosterone was thought to be the circulating androgen in blood.
TABLE III

Dihydrotestosterone in Ovarian Vein and

Peripheral Plasma of Women during Laparatomy*

\begin{tabular}{ccc}
\hline Subject & Peripheral & Ovarian vein \\
\hline & \multicolumn{2}{c}{$m \mu g / 100 m l$} \\
1 & 8.2 & 7.8 \\
2 & 6.0 & 12.9 \\
3 & 16.0 & 23.0 \\
\hline
\end{tabular}

* Plasma samples obtained from Doctors J. Lobotsky and C. W. Lloyd.

Hormone binding at the site of action is considered an essential event in hormone action. Wilson and coworkers observed that dihydrotestosterone, a potent androgen, binds with higher affinity to nuclear chromatin of prostate and seminal vesicle than does testosterone $(5,15)$. Their in vitro work suggests that testosterone is rapidly and efficiently converted to dihydrotestosterone by a $5 \alpha$-reductase located in the nucleus. In vitro dihydrotestosterone is formed in large amounts only in accessory sex tissues. In one tissue, skin, this group reported a much higher conversion by perineal sexual skin than skin from other sites (16). It should be noted that lack of conversion by muscle from 11 different species indicates that formation is not required to explain all known androgen effects (17). After an injection of labeled testosterone into the intact animal, small amounts of labeled dihydrotestosterone appeared in blood.

Using techniques developed to quantitate steroid conversion rates in the circulation and a sensitive plasma dihydrotestosterone assay, we have attempted to measure blood production or secretion rates and to determine whether plasma dihydrotestosterone is the result of direct secretion or reflects peripheral events.

As suggested by the affinity studies with the plasmabinding protein, the metabolic clearance rates in both males and females are significantly lower in each respective sex than the testosterone clearance rates. $\mathrm{Di}$ hydrotestosterone blood production rates were $302 \pm 65$ $\mu \mathrm{g} /$ day in six males and only $56 \pm 26 \mu \mathrm{g} /$ day in four females. Blood production rates of dihydrotestosterone were also much lower than testosterone blood production in the respective sex. The testosterone/dihydrotestosterone production rate ratio in the female was approximately $5: 1$. In both males and females therefore, the plasma concentration and production rate of DHT are only fractions of testosterone production. 
A significant amount of testosterone infused into the general circulation is converted to dihydrotestosterone. The conversion ratio, $\mathrm{C}_{\mathbf{B B}}{ }^{\mathrm{T}}{ }^{\mathrm{DH} T}$, is $5.6 \pm 0.6 \%$ in the male and $3.5 \pm 0.4$ in the female. The transfer factor $[\rho]_{\mathrm{BB}}{ }^{\mathrm{T}-\mathrm{DHT}}$ is $3.9 \pm 1.0 \%$ in the male and $1.7 \pm 0.6 \%$ in the female. As has been observed in previous studies of androstenedione-testosterone (2) and testosterone-estradiol and androstenedione-estrone conversions (4), there is a significantly higher conversion ratio or transfer constant in the male. In three females, the conversion ratio of androstenedione to dihydrotestosterone $\left(\mathrm{C}_{\mathbf{B B}}{ }^{\mathrm{A}-\mathrm{DHT}}\right)$ was $9.2 \%$. Since plasma testosterone and dihydrotestosterone were measured simultaneously with the conversion data in these patients, a direct calculation indicating the contribution of the plasma precursor to dihydrotestosterone in plasma can be obtained. Despite the difference in conversion ratios seen in the male and female, the major factor appears to be the excess of precursor testosterone present in male plasma. As a result of this, approximately three-fourths of the plasma dihydrotestosterone is derived from the peripheral conversion of testosterone in the male, but less than $20 \%$ in the female. The studies of androstenedione-dihydrotestosterone conversion indicate that androstenedione is also a precursor (prehormone) for plasma dihydrotestosterone. When the conversion ratio $\left(\mathrm{CR}_{\mathbf{B}} \mathbf{B}^{\mathrm{A}-\mathrm{DHT}}\right)$ is considered together with published values for plasma androstenedione (mean $116 \mathrm{~m} \mu \mathrm{g} / 100 \mathrm{ml}$ in male and $159 \mathrm{~m} \mu \mathrm{g} / 100 \mathrm{ml}$ in the female [10]) these data suggest that the remaining plasma dihydrotestosterone, not accounted for by testosterone, may be derived from peripheral conversion of androstenedione. Testosterone is the major source (prehormone) of plasma dihydrotestosterone in the male, while androstenedione appears to be the major prehormone for blood dihydrotestosterone in the adult female. This study therefore would suggest that blood dihydrotestosterone is not a secretion product in either of the sexes. Further support for this concept is provided by a direct comparison of peripheral and ovarian vein dihydrotestosterone levels where a minimal gradient was detected in three women.

As expected from consideration of steroid structure and in vitro experience (18), no back conversion of the $5 \alpha$-androstane steroid to the 4 -androstene type steroid was detected from these blood studies.

This study suggests that there is a different kind of hormone circulating in plasma. Previous conversion products, such as testosterone in the female and estradiol in the male, appear to be the results of both peripheral conversion and direct secretion (1). The precursor prehormone) has been inactive or has possessed differ- ent biological properties than the product in blood. In the present situation of testosterone-dihydrotestosterone in the male, there is conversion of an active androgen into a similarly active androgen. However, in the female the previous pattern again appears. Testosterone is a minor prehormone, but androstenedione, a very weak androgen, appears to be the major precursor for plasma dihydrotestosterone. This investigation suggests that dihydrotestosterone is not a secreted steroid in females but that blood dihydrotestosterone is derived from both androstenedione and testosterone peripheral conversion. Although this work indicates a peripheral, nonendocrine tissue source for dihydrotestosterone, it is not possible to indicate whether synthesis occurs in hepatic or androgen target tissues. This is now an important question since blood dihydrotestosterone may be an important reflection of androgen events occurring in target tissues.

\section{ACKNOWLEDGMENTS}

This work was supported by grants from the U. S. Public Health Service (AM-13710) and from the American Cancer Society (P 404D).

\section{REFERENCES}

1. Baird, D., R. Horton, C. Longcope, and J. F. Tait. 1969. Steroid dynamics under steady-state conditions. Recent Progr. Hormone Res. 25: 611.

2. Horton, R., and J. F. Tait. 1966. Androstenedione production and interconversion rates measured in peripheral blood and studies on the possible site of its conversion to testosterone. J. Clin. Invest. 45: 301.

3. Longcope, C., D. Layne, and J. F. Tait. 1968. Metabolic clearance rates and interconversions of estrone and $17 \beta$ estradiol in normal males and females. J. Clin. Invest. 47: 93.

4. Longcope, C., T. Kato, and R. Horton. 1969. Conversion of blood androgens to estrogens in normal adult men and women. J. Clin. Invest. 48: 2191.

5. Wilson, J., N. Bruchovsky, and J. Chatfield. 1967. Intranuclear localization of testosterone-1, $2^{3} \mathrm{H}$ in rat prostate. Proc. Int. Congr. Endocrinol. 3rd. 184: 17.

6. Ito, T., and R. Horton. 1970. Dihydrotestosterone in human peripheral plasma. J. Clin. Endocrinol. Metab. $31: 362$.

7. Horton, R., and J. F. Tait. 1967. In vivc conversion of dehydroisoandrosterone to plasma androstenedione and testosterone in man. J. Clin. Endocrinol. Metab. $27: 79$.

8. Kato, T., and R. Horton. 1968. A rapid method for the estimation of testosterone in female plasma. Steroids. 12: 631 .

9. Tait, J. F., and R. Horton. 1966. In Steroid Dynamics. G. Pincus, T. Nakao, and J. F. Tait, editors. Academic Press Inc., New York. 393.

10. Baird, D., R. Horton, C. Longcope, and J. F. Tait. 1969. Steroid prehormones. Perspec. Biol. Med. 11: 384. 
11. Kato, T., and R. Horton. 1968. Studies of testosterone binding globulin. J. Clin. Endocrinol. Metab. 28: 1160.

12. Vermeulen, A., and L. Verdonck. 1970. Testosterone assays by competitive protein binding in steroid assay by protein binding. Acto Endocrinol. Suppl. 147: 239.

13. Korenman, S. G. 1969. Comparative binding affinity of estrogens and its relation to estrogenic potency. Steroids. 13: 163.

14. Herman, T., G. Fimognari, and I. Edelman. 1968. Studies on renal aldosterone-binding proteins. J. Biol. Chem. 243: 3849 .

15. Bruchovsky, N., and J. Wilson. 1968. The conversion of testosterone to $5 \alpha$-androstan-17 $\beta$-ol-3-one by rat prostate in vivo and in vitro. J. Biol. Chem. 243: 2012.

16. Wilson, J., and J. Walker. 1969. The conversion of testosterone to $5 \alpha$-androstan-17 $\beta$-ol-3-one (dihydrotestosterone) by skin slices of man. J. Clin. Invest. 48: 371.

17. Gloyna, R., and J. Wilson. 1969. A comparative study of the conversion of testosterone to $17 \beta$-hydroxy-5 $\alpha$ androstan-3-one (hydrotestosterone) by prostate and epididymis. J. Clin. Endocrinol. Metab. 29: 970.

18. McGuire, J., V. Hollis, Jr., and G. Tomkins. 1960. Some characteristics of the microsomal steroid reductases $(5 \alpha)$ of rat liver. J. Biol. Chem. 235: 3112. 